\title{
Timing Human Response in Real Fires
}

\author{
PATRICIA BRENNAN \\ Centre for Environmental Safety and Risk Engineering \\ Victoria University of Technology \\ PO Box 14428 MCMC, Melbourne, Victoria 8001, Australia
}

\begin{abstract}
Reliable data on time use by occupants in real fire incidents, particularly for the period prior to the initiation of evacuation, is required to support time-dependent risk assessment models. However, such data is difficult to obtain. The times for occupants to start and complete evacuation in two fire incidents in high-rise buildings (an office and a residential building) are presented to demonstrate that time use can be estimated post incident by re-constructing information from occupants and combining it with the few precise times that are available in a fire incident. These times are compared with times from simulated emergencies. The contrasting incidents show marked differences in time to start evacuation with long delays occurring in the apartment building.
\end{abstract}

KEY WORDS: Human Behaviour in Fires, Response Time in Fires, Evacuation

\section{INTRODUCTION}

Interest in time use by occupants during fires in buildings was a major reason for the introduction of studies into human behaviour in fires as time lost prior to taking effective avoidance action was crucial to safety. A quarter of a century ago in one of the first major investigations of human response in fires, Wood [1] acknowledged that the lack of indication of time taken for any one action was a major limitation in the value of his data. However, until the demand came from fire engineering and risk modelling, the primary goal of quantitative data gathering was to describe and explain the behaviour of occupants during a fire. Models of time use were developed [eg. 2] but reports linking behaviour to real time [eg. 3] were uncommon. 
In time-dependent risk assessment models such as that of Beck and Yung [4], sub-systems are used to describe

- the development and spread of fire, smoke and toxic products

- the response of building detection and suppression systems and other building parameters and

- the response of people to the changing external environment, a process complicated by psychological and social factors.

While building codes and regulations do not in general deal with time loss prior to egress movement, such information is essential for inclusion in risk models. To calculate the risk to life of occupants, behavioural information is needed on

- the type of actions and patterns of behaviour that occur, including those that affect fire development and control

- the probability of the occurrence of such actions (and of inactivity) by different populations and in different occupancies as a response to awareness of changes in the environment and

- time taken for actions and periods of inactivity.

Field and experimental studies have provided information on actions and their probabilities and delineated the common patterns of response sequences, but the third area, the quantification of time, has remained elusive and especially so for the early stages of a fire in non-public buildings. While response sequences reflect time, they do not establish it. Similar actions can have very different times and summary statistics need to establish the range for different occupancies and different groups within occupancies. Studies which map occupant movement [eg. 5] also have not put precise times to movements.

The relative effectiveness of different warning systems in communicating the message and so initiating action has been investigated experimentally [eg. 6, 7]. Evacuation studies, most notably Pauls [8], commonly provide information on movement out of a building and the times for such movement once started. More recent research has shown increasing attention to time [eg. 9]. At the National Research Council of Canada attention is given to the time to begin evacuation as well as to movement time during simulated emergencies in residential buildings [eg. 10, 11].

In quantifying time use in real life fire incidents, relying solely on occupants to estimate times alone is unsatisfactory. Proulx et al [12] note a tendency to give round figures and the striking inaccuracy of some individuals in assessing time in hours let alone minutes in their report on behaviour in a real fire. At the Centre for Environmental Safety and Risk Engineering different approaches are being tested in order to increase confidence in time estimations. Re-enacting and estimating time for short sequences of actions offers the prospect of increasing the accuracy of estimates since asking individuals for the time to complete specific activities reduces the complexity of the task. Present experience suggests that perceived duration fluctuates with the urgency of the situation and the amount of activity undertaken. 


\section{METHODOLOGY}

The time-based accounts of events in two fire emergencies presented below (Tables 1 and 2) are obtained by combining many sources of information, but rely principally on occupants' recall of perceptions and actions. Intensive interviewing of occupants is a key source of data. It is time consuming, as is the later piecing together of information.

\section{Method of interview}

The interview technique adopted is based on the Behavioural Sequence Interview Technique developed by Keating and Loftus [13] to promote accuracy of recall. Individual interviews are held within a maximum of four weeks from the incident date. Occupants are first encouraged to give an unstructured account of their experience. This is recorded. A written account is then developed with the interviewer. It concentrates on locating perceptions and responses in a sequential framework, taking each action and nominating its immediate precursor (cue) and the reasons for the action. Observations of cues which can be considered more peripheral in that they are not nominated as directly affecting response, such as the behaviour of other occupants or the level of smoke in other areas of the building, are also recorded as mentioned and specifically asked for at the end of the interview process if not.

Fixed times are obtained from fire brigades and other services. In office fires in particular, saving work is often the last action by employees before evacuating and if such computer times can be accessed they provide a valuable source of data.

\section{Incidents investigated}

Incident 1 was a fire in an office building which occurred at 14:32 hours on a working day. It was a severe fire on the third level (2nd floor) of a fourteen storey building. The fire was confined to Level 3 but smoke from $140+$ polyurethane-padded chairs at its centre created a major hazard on the upper floors as well as on the fire floor. All six occupants from a Level 3 office and all three staff from a Level 13 office were trapped by smoke and retreated to rooms which eventually became smoke logged. The Level 3 people were overcome by smoke before being rescued by firefighters. All other occupants, evacuated safely via fire stairs.

The fire brigade was alerted at the same time as the occupants of one office on the fire floor discovered the fire, which was well advanced. The public address system was used after most people had left and after firefighters arrived. Alarms did not sound. Most occupants had participated in fire drills. The building extended some 52 metres from one city street to another. Occupants trapped on the third level were at the 'back' of the building while most fire service units went to the 'front'. This delayed their recognition by firefighters.

There were about 250 people in the building. This report restricts itself to the response on four floors - Levels 13, 12, 4 and 3 (fire floor). The occupancy of these levels was as follows:

Level No. tenancies Total population No. interviewed

$\begin{array}{rrcr}13 & 3 & 25 & 22 \\ 12 & 1 & 10 & 6 \\ 4 & 1 & 65 \text { (approx.) } & 1 \\ 3 & 2 & 7 & 7\end{array}$


The account of the one manager from Level 4 received some confirmation from the observations reported by people from other floors. Levels 7-11 of the building were unoccupied and Levels 5-6 were partly occupied with few people present. The estimated 150 on two floors below the fire were alerted later than other floors and evacuated later.

Incident 2 was a fire in an 18 storey residential building of about 120 apartments. Above the first two floors, most floors had 8 apartments but some apartments had been combined. The fire occurred at about 03:30 hours. It was seen by a person outside the building who alerted the night manager at about the same time that the occupant awoke. The fire was confined to one corner apartment on the third floor and was reported as extinguished by the time of the arrival of the fire services. Smoke spread through the corridors on the upper floors but visibility was not greatly restricted. There were two staircases on either side of the central lifts but no dedicated fire stairs.

The building alarm was the first cue for most occupants. The fire brigade was alerted at the same time. Some rooms had posted instructions on what to do in a fire emergency but no drills had taken place.

There were an estimated 200 people present at the time of the fire, most of whom were retired couples or young people. Fewer than half that number actually evacuated, a statistic that carries considerable significance for models of human response. The population was predominantly transient, many staying for only two or three days. Twenty seven occupants from twenty three apartments on thirteen levels (representing 33 people) were interviewed. The number of people available for interviews was limited (two coachloads of holiday makers left within two days of the fire). About $60 \%$ of interviewees were permanent residents and about half of the remainder were familiar with the building as they stayed for weeks at a time and returned yearly. The response of the person in the apartment of fire origin, who was not interviewed, has been reconstructed from the accounts of other witnesses. Responses of a few other occupants are also known but not included here because observations were not confirmed by a second witness.

\section{Analysis}

The time of cues, the movement sequence and the duration of such movement are ascertained for each interviewee. This involves applying a jigsaw-like approach to the raw data. Observations of the alarm or other warnings, of smoke and fire cues, of the actions of other occupants, of fire vehicles and firefighters are placed in time, working multi-directionally. In both incidents, times provided by the direct link between the building alarm systems and the fire brigade and for the arrival at the scene of the fire brigade and other support vehicles are central to the analysis. Occupants are usually able to recall visual details such as the number of fire trucks or other vehicles present when they exit a building, where they first saw fire fighters, and the state of the fire from specific locations. These provide clues to times as they can be linked with fire service records which are more accurate.

Interviewees frequently provide unexpected information on times. In the office fire, for example, the time of the alert for Tenancy A on Level 4 was fixed because an employee had just saved a computer file and was able to retrieve the time later. As individuals recount the 
event in sequential detail, they recall actions like asking someone for the time on exiting the building, realising they had missed an appointment, making a phone call to another person, or having just heard or seen a particular segment of a TV/radio broadcast. They often mention observation of an event for which the interviewer has a fixed time. When a number of people in a particular location are interviewed perceptions can be cross checked. This not only allows the accuracy of individual accounts to be assessed but establishes movements of people in relation to one another within and across locations.

The times for occupant response presented in this paper remain as estimates. In calculating speed of response and movement, consideration is given to details like the duration of discussions with others, waiting for others and helping others. This attempt to reduce the time to 60 second intervals is ambitious, even over-ambitious with respect to the second incident, but is made here with the purpose of demonstrating the methodology. Refinements in data collection are being introduced as experience in estimating times for an incident from collected data highlights gaps in the process.

\section{FINDINGS ON RESPONSE TIMES}

Time of (ie. clock time) and time for (ie. duration) events and responses during the two fire incidents, which are chosen for their contrast, are given in Tables 1 and 2.

Times and perceptions of events for the daytime office building fire were relatively easy to obtain. The fact that office occupants tend to move as a unit was advantageous. The second incident represented a more difficult scenario for obtaining data on times as the fire occurred at night in a residential building and many occupants could not be contacted. Furthermore, few people aroused from sleep in the early hours of the morning by a fire emergency recall precise times even if they noted them on waking.

Table 1 presents a sequential breakdown of events, tenancy by tenancy, on four floors of the office building affected by the fire during the first 20 minutes after the fire was noted. It also provides some key details of the fire development and fire brigade response.

Table 2 shows the time of occurrence of events in the residential building during the first twenty minutes after the fire had started to develop. It includes information on the fire, the fire brigade and the significant part played in fire fighting by the Night Security Manager. Each apartment is treated as a unit, but any separation of flat occupants during the course of the event is described. This report makes no attempt to describe behaviour during the period before occupants left their apartments as it is focussing on times related to evacuation. Suffice it to say that, except on the fire floor in the apartment building, investigative behaviour was generally limited to checking the immediate area outside the office or apartment.

Table 3 gives the time taken from when occupants in any one location received the first cue until they actually began to evacuate ie. started to move directly out of the building. Thus any time used in preparing to evacuate after making the decision to leave is included. There is a marked difference in the time to respond between office and residential occupancies, at least as indicated by the two selected incidents. While differences in the severity of the fires and 
TABLE 1. Office building: Timing of events (in minutes) based on reports of occupants and fire brigade. (Page 1)

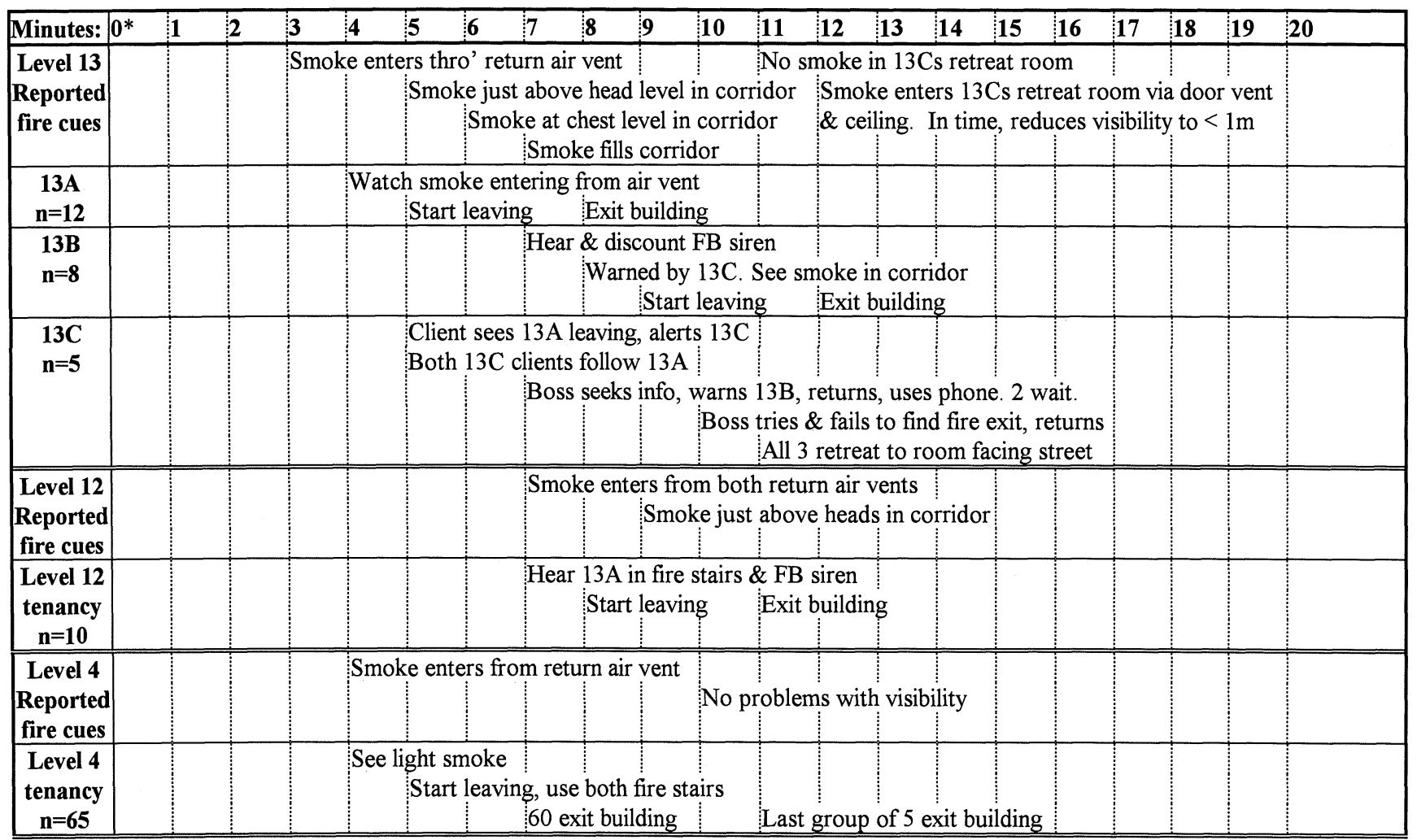




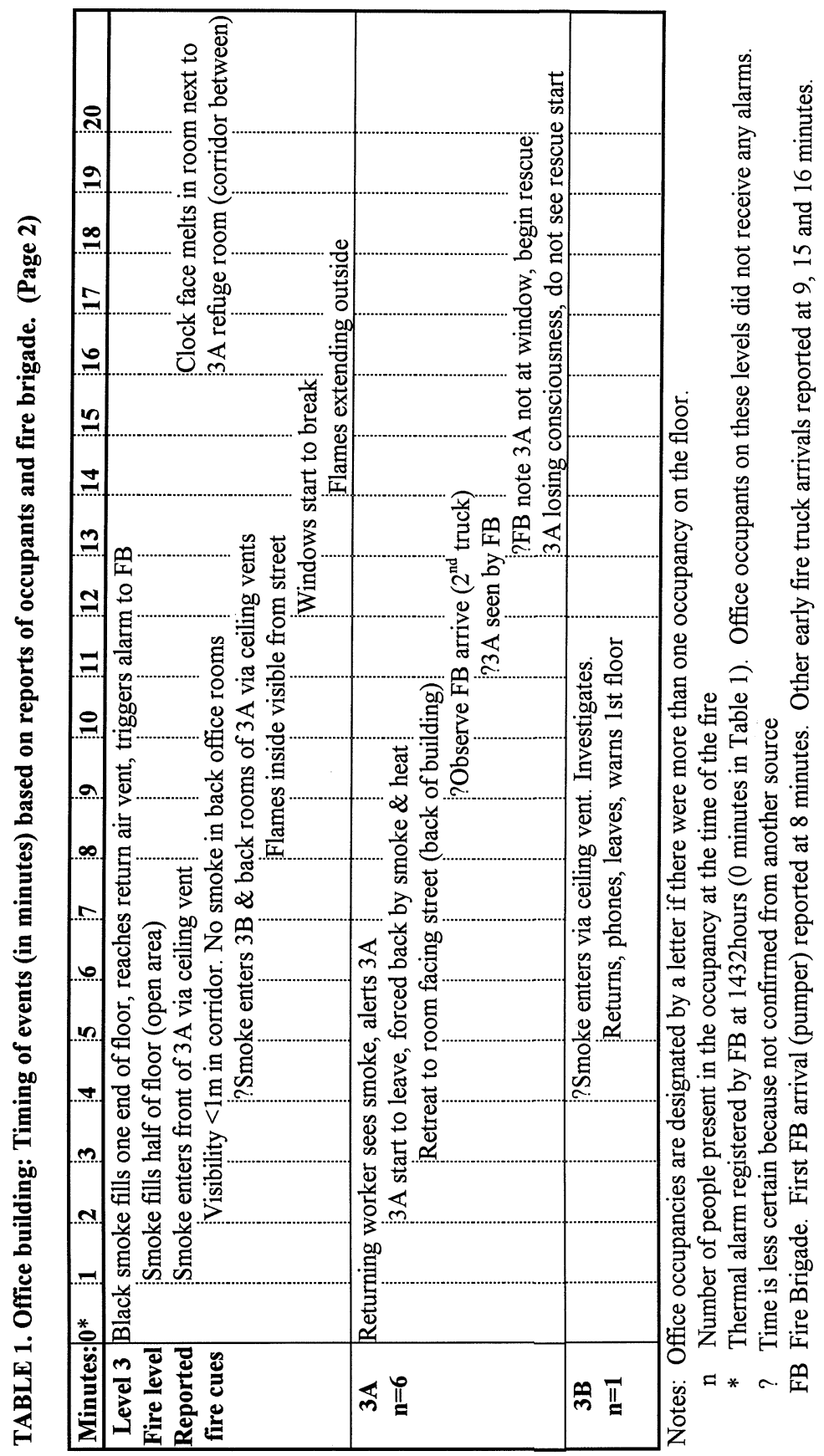




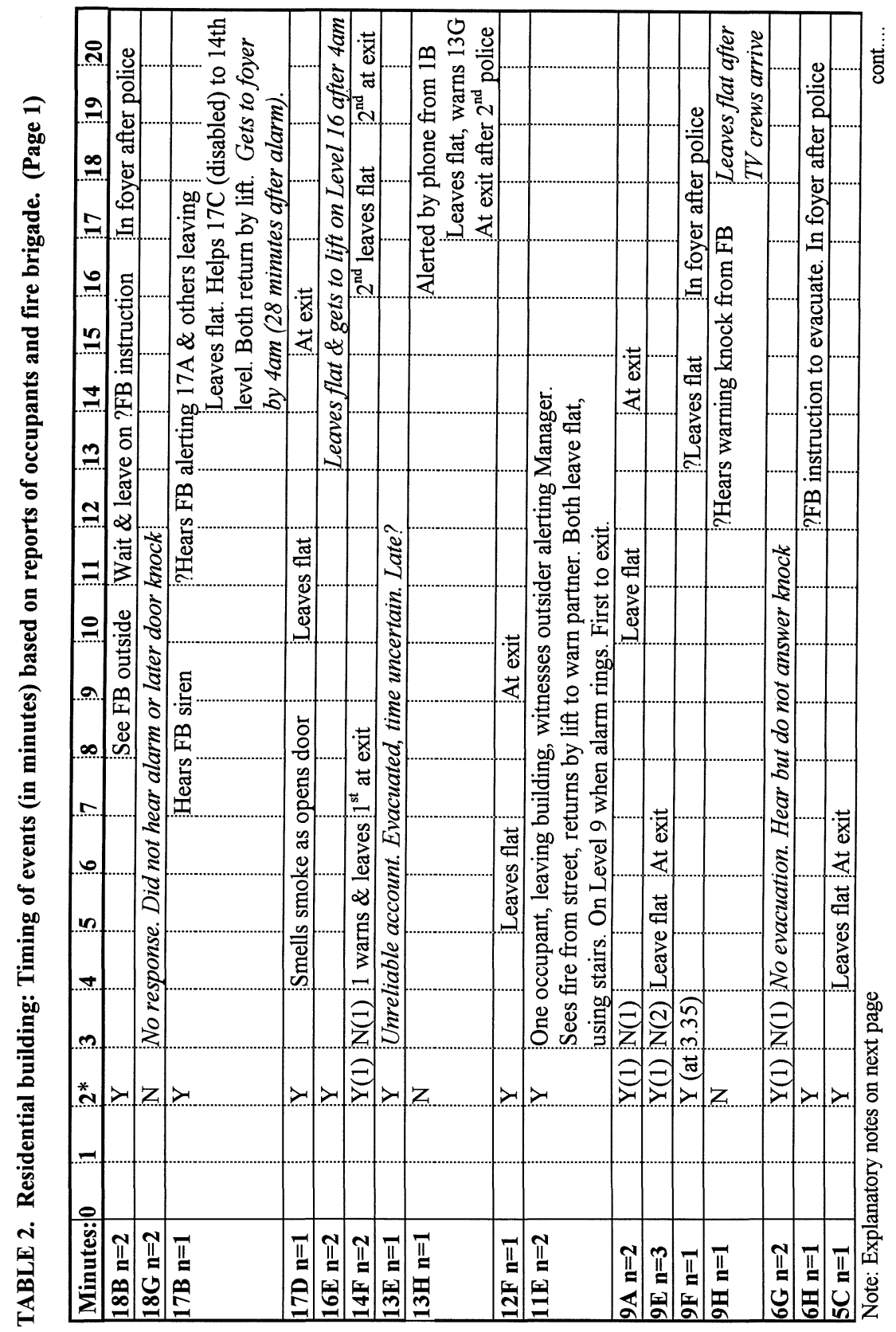


TABLE 2. Residential building: Timing of events (in minutes) based on reports of occupants and fire brigade. (Page 2)

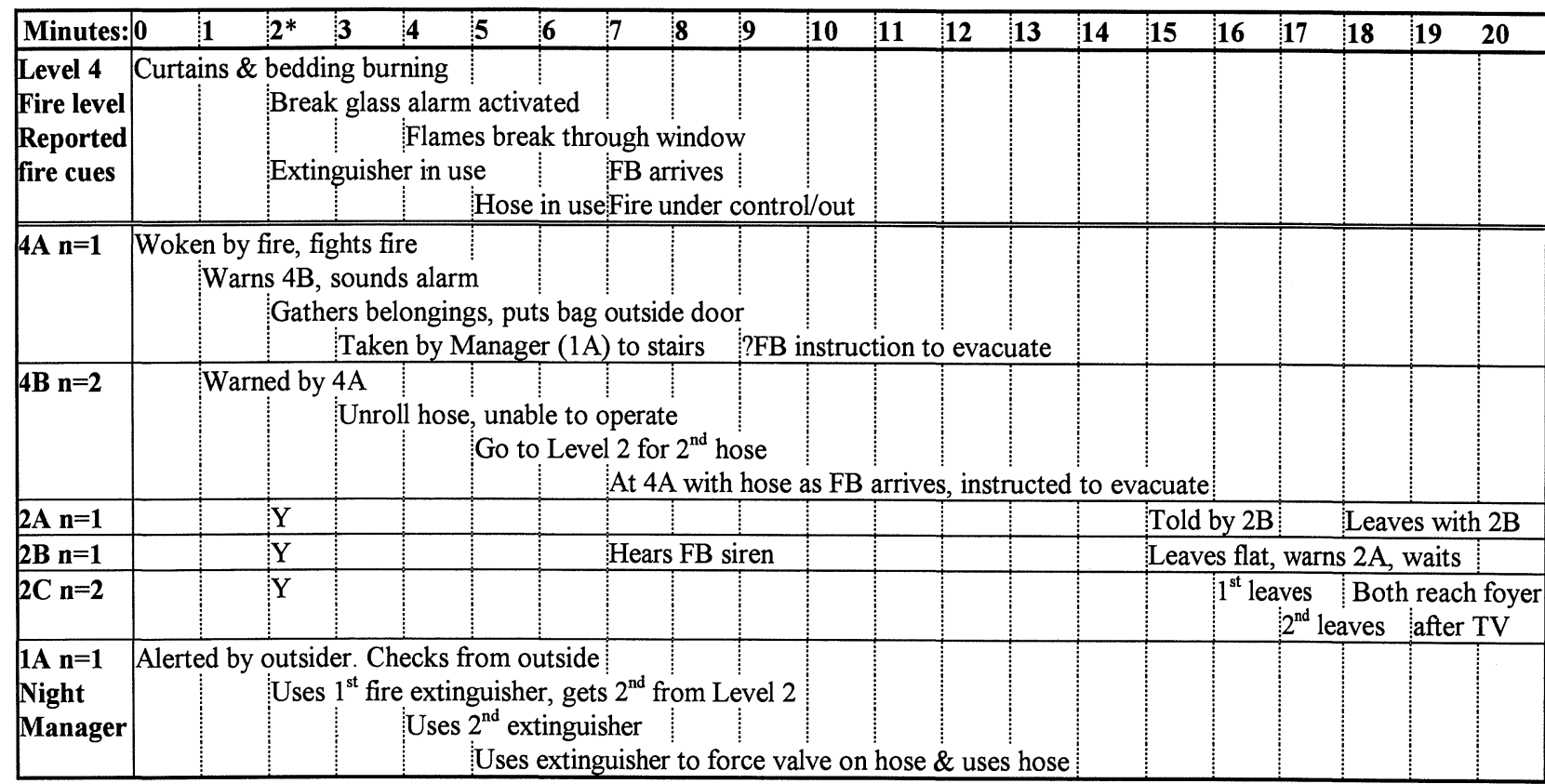

Notes: Apartments are designated by level and letter. $\mathrm{N}=$ number of people present (eg. 1A is a ground floor apartment, 1 person present)

* Alarm and 000 call received by FB at 0332 hours (2 minutes in Table 2)

$\mathrm{Y}$ Heard building alarm. N Did not hear alarm

? Time is less certain because not confirmed from another source

FB Fire Brigade. Arrival reported at 0337 hours (07 minutes in Table 2). 3 FB trucks at 09 minutes

Ambulance arrives at 14 minutes. Police arrive at 15 minutes. TV crews arrive after police (time not ascertained). 
consequent spread of smoke and in the times of the fires play a significant role, the quicker response in the office setting is also influenced by training, the ease of communication across a floor, readiness to evacuate and unity in response.

In the office building, where smoke was the predominant cue, responses were comparatively rapid and effective with most people leaving within a minute or two of the appearance of smoke. Occupants gathered in office groups and left together. The exception was one group of five people who remained an extra five minutes to arrange for phone calls to be diverted, a task which they first had to learn. The trapped occupants of $3 \mathrm{~A}$ grouped as trained but had to enter the area where the fire was in order to reach the fire exit a few metres from their door. The fire could not be seen, but choking smoke and heat drove them back. They did not react differently from people on other floors but were beaten by the rapidity of fire development and their location. The $13 \mathrm{C}$ occupants were new to the building and had not experienced an evacuation drill. There was considerable delay before an effective response was instigated during which actions not immediately directed to leaving were pursued.

TABLE 3: Estimated interval in minutes from reception of first cue in each location to start of evacuation

\section{Office Building}

$\begin{array}{lc}\text { Location } & \text { Cue-Start (minutes) } \\ \text { 3A } & 2 \text { (Trapped) } \\ \text { 3B } & 1 \\ \text { 4 (Main group) } & 1 \\ \text { 4 (Group 2) } & 5 \\ \text { 12 } & 1 \\ \text { 13A } & 1 \\ \text { 13B } & 2 \\ \text { 13C } & 5 \text { (Trapped) } \\ \end{array}$

\begin{tabular}{cccc} 
Location & \multicolumn{2}{c}{ 2. Residential Building } & \\
Cue-Start (minutes) & Location & Cue-Start (minutes) \\
Flat 1A & No evac'n (Fights fire) & $9 \mathrm{H}$ & 16 \\
Flat 2A & 16 & $11 \mathrm{E}$ & 1 \\
2B & 16 & $12 \mathrm{~F}$ & 3 \\
2C(n=1) & 14 & $13 \mathrm{E}$ & $?$ \\
$2 \mathrm{C}(\mathrm{n}=1)$ & 15 & $13 \mathrm{H}$ & 1 \\
$4 \mathrm{~B}$ & 8 (Fight fire first) & $14 \mathrm{~F}(\mathrm{n}=1)$ & 2 \\
5C & 2 & $14 \mathrm{~F}(\mathrm{n}=1)$ & 14 \\
$6 \mathrm{G}$ & No evacuation & $16 \mathrm{E}$ & $20+$ \\
$6 \mathrm{H}$ & 13 & $17 \mathrm{~B}$ & 12 \\
$9 \mathrm{~A}$ & 8 & $17 \mathrm{D}$ & 8 \\
$9 \mathrm{E}$ & 2 & $18 \mathrm{~B}$ & 10 \\
$9 \mathrm{~F}$ & 10 & $18 \mathrm{G}$ & No evacuation \\
& & & \\
\hline
\end{tabular}


Responses in the residential building were more varied and complex. The slow response of residential occupants to alarms in this particular building was due to a number of intervening variables. Age was a factor. Many of the temporary occupants were over sixty-five and took considerable time preparing to evacuate. Some of the delay in Incident 2 can be explained by the time of the incident. The time it took for people to wake in response to the building alarm was not ascertained - such data are better obtained from experimental studies [eg.14]. About $30 \%$ of the occupants who were asleep did not wake to the alarm. Five people in the sample were woken by other flat occupants and one or two reported fighting to go back to sleep in spite of the alarm.

Many residents waited for further indications of the existence of an emergency and left as a result of instructions from fire brigade personnel. One person had such faith in the local fire services that she saw no reason to evacuate for any fire. Experience of false alarms, confusion between the building alarm and car alarms which were frequent in the area, and ignorance of the meaning of the alarm were common causes of delay. Failure to respond to a warning knock alone was associated with previous experience of similar disturbances from tenants and was a safety issue - answering a door to an unidentified caller in the middle of the night in this particular building was regarded by some as foolhardy.

The time from first alert to the start of evacuation varied from one to about six minutes in the office building fire incident and from one minute to over twenty minutes in the case of the residential apartment building. The range of the latter is comparable with the thirty seconds to over twenty-four minutes to start evacuation in waking hours for non-naive subjects in trial evacuations reported by Proulx [10]. Those residents too were responding to similar cues - a building alarm, presence of the fire brigade, warnings from fire brigade personnel, and direct or indirect warnings from others. In the incident under discussion, the additional cue from the fire itself, smoke, became relevant when occupants opened the door to their apartment. This external investigation was for many the factor that precipitated the decision to evacuate.

The most noticeable feature of residential evacuations is the wide range of times from receipt of the first cue to the start of egress movement for apartments receiving similar cues, even for those on the same floor. Consequently, evacuation appears as a more random process even though occupants of individual apartments tend to act as a unit. Duration of the evacuation period is dominated by the time taken for the initial response period which is in large part a function of the cues received.

\section{CONCLUSION}

While studies of simulated emergencies provide valuable information on times and movement of people and experimental studies can be made of response to alarms, the role of physical cues from the fire and their interaction with other cues in influencing responses and the speed of response can only be understood by examining specific fire incidents. As reliable figures are required for fire engineering and risk assessment modelling, continuing research is needed to find means to counter the likely inaccuracy of occupant time estimations. The recounting of the experience of a fire in a sequential episodic format is one method by which times for occupant response in fires in buildings can be re-constructed. The information can be combined with data from other sources to establish the time of arrival of cues in a section of a 
building, the recognition of their significance and the time to start and complete evacuation. Present methods are revealing but time-consuming; they will be refined as experience in data collection in this area is expanded.

\section{REFERENCES}

1. Wood, P.G. "The behaviour of people in fires" Fire Research Note No. 953. Building Research Establishment Fire Research Studies, Borehamwood, U.K.: Department of the Environment and Fire Offices Committee Joint Fire Research Organization, 1972.

2. Sime, J. D. "Perceived time available: The margin of safety in fires", Fire Safety Science Proceedings of the First International Symposium, pp. 561-573, 1986.

3. Lerup, L., Cronrath, D. \& Liu, J.K.C. "Fires in nursing facilities" in Fires and Human Behaviour, ed. D. Canter, pp.155-180, John Wiley \& Sons, London, 1980.

4. Beck, V.R. \& Yung, D. "The development of a risk-cost assessment model for the evaluation of fire safety in buildings", Fire Safety Science - Proceedings of the Fourth International Symposium, International Association for Fire Safety Science, pp. 817-828, 1994.

5. Sime, J., Breaux, J. \& Canter, D. "Human behaviour patterns in domestic and hospital fires" Building Research Establishment Occasional Paper, Fire Research Station, Borehamwood, U..K., May 1994.

6. Bellamy, L.L., \& Geyer, T.A.W. "Experimental programme to investigate informative fire warning characteristics for motivating fast evacuation" Building Research Establishment Report, Fire Research Station, Borehamwood, U..K., 1990.

7. Keating, J. \& Loftus, E. "Vocal alarm systems for high-rise buildings - a case study", Mass Emergencies, 2:1, 25-34, 1977.

8. Pauls, J. "Movement of people", in Handbook of Fire Protection Engineering, Section 1, Chapter 15. Quincy, MA: National Fire Protection Association. 1988.

9. Fahy, R.F. \& Proulx, G. "Collective common sense: A study of human behaviour during the World Trade Centre evacuation", NFPA Journal, 59-67, March/April 1995.

10. Proulx, G. "The time delay to start evacuating upon hearing a fire alarm", Proceedings of the Human Factors and Ergonomics Society 38th Annual Meeting, pp. 811-815, 1994.

11. Proulx, G. "Evacuation time and movement in apartment buildings", Fire Safety Journal, 24, 229-246, 1995.

12. Proulx, G., Pineau, J., Latour, J.C. \& Stewart, L. "Study of the Occupants' Behaviour during the 2 Forest Laneway Fire in North York, Ontario, January 6, 1995", National Research Council of Canada Internal Report No. 705, September 1995.

13. Keating, J.P, \& Loftus, E.L. "Post-fire interviews: Development and field validation of the Behavioural Sequence Interview Technique", NBS-GCR-84-477 National Bureau of Standards, Centre for Fire Research, MD. 1984.

14. Bruck, D. \& Horasan, M. "Non-arousal and non-action of normal sleepers in response to a smoke detector alarm", Fire Safety Journal, 25, 125-139, 1995.

\section{ACKNOWLEDGEMENT}

This research is supported by an Australian Research Council Collaborative Research Grant, funded in conjunction with BHP and the National Association of Forest Industries. The author would like to thank the interviewees and the Fire Services of New South Wales and Queensland for their assistance. 